\title{
Analytical system for stable carbon isotope measurements of low molecular weight $\left(\mathrm{C}_{2}-\mathrm{C}_{6}\right)$ hydrocarbons
}

\author{
A. Zuiderweg, R. Holzinger, and T. Röckmann \\ Atmospheric Physics and Chemistry Group, Institute for Marine and Atmospheric research Utrecht, Utrecht University, \\ Utrecht, The Netherlands \\ Received: 14 December 2010 - Published in Atmos. Meas. Tech. Discuss.: 11 January 2011 \\ Revised: 2 June 2011 - Accepted: 8 June 2011 - Published: 22 June 2011
}

\begin{abstract}
We present setup, testing and initial results from a new automated system for stable carbon isotope ratio measurements on $\mathrm{C}_{2}$ to $\mathrm{C}_{6}$ atmospheric hydrocarbons. The inlet system allows analysis of trace gases from air samples ranging from a few liters for urban samples and samples with high mixing ratios, to many tens of liters for samples from remote unpolluted regions with very low mixing ratios. The centerpiece of the sample preparation is the separation trap, which is used to separate $\mathrm{CO}_{2}$ and methane from the compounds of interest. The main features of the system are (i) the capability to sample up to 3001 of air, (ii) long term (since May 2009) operational $\delta^{13} \mathrm{C}$ accuracy levels in the range $0.3-0.8 \%$ (1$\sigma$ ), and (iii) detection limits of order $1.5-2.5 \mathrm{ngC}$ (collected amount of substance) for all reported compounds.

The first application of this system was the analysis of 21 ambient air samples taken during $48 \mathrm{~h}$ in August 2009 in Utrecht, the Netherlands. Results obtained are generally in good agreement with those from similar urban ambient air studies. Short sample intervals allowed by the design of the instrument help to illustrate the complex diurnal behavior of hydrocarbons in an urban environment, where diverse sources, dynamical processes, and chemical reactions are present.
\end{abstract}

\section{Introduction}

A significant amount of the total reactive carbon input (estimated as near $1150 \mathrm{Tg} \mathrm{yr}^{-1}$, Guenther et al., 1995) to the atmosphere consists of non-methane hydrocarbons (NMHCs).

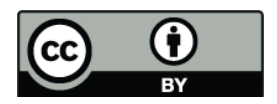

Correspondence to: A. Zuiderweg (azuider@gmail.com)
These are emitted to the atmosphere through many processes, both natural as a product of vegetative growth, decay and natural combustion of plant material, and anthropogenic including biomass burning for energy or heating, fossil fuel combustion, and industrial processes. Nonmethane hydrocarbons play important roles in atmospheric chemistry contributing to the production of tropospheric ozone and resultant photochemical pollution, the formation of aerosol particles, and the oxidative capacity of the atmosphere (Warneck, 1988; Seinfeld and Pandis, 1998; Goldstein and Galbally, 2007).

Low molecular weight NMHC, consisting of compounds with 2 to 7 carbon atoms $\left(C_{2}\right.$ to $\left.C_{7}\right)$, account for the vast majority of anthropogenic emissions to the troposphere (Middleton, 1995). Acetylene, ethylene, propyne, and propylene originate primarily from combustion processes such as fossil fuel combustion and biomass burning; alkanes mainly stem from natural gas leakage and petroleum product evaporation, with significant transportation sources as well; and aromatic compounds mainly from transportation sources and solvent evaporation (Goldstein and Shaw, 2003; Redeker et al., 2007). Oxidative processes provide the atmospheric removal mechanism of NMHC compounds, mainly through reaction with $\mathrm{OH}$, which is by far the dominant process (Conny and Currie, 1996):

$\mathrm{RH}+\mathrm{OH} \rightarrow \mathrm{R}+\mathrm{H}_{2} \mathrm{O}$

Where R stands for any alkyl radical remaining after hydrogen abstraction from the hydrocarbon RH. Other removal mechanisms include $\mathrm{NO}_{3}, \mathrm{Cl}$, or $\mathrm{O}_{3}$ (Warneck, 1988; Seinfeld and Pandis, 1998; Brenninkmeijer, 2009).

The minor stable isotope of carbon, ${ }^{13} \mathrm{C}$, has an average natural abundance of approximately $1.1 \%$. Biological (e.g. photosynthesis), physical (e.g. diffusion) and chemical

Published by Copernicus Publications on behalf of the European Geosciences Union. 
processes often act slightly differently on isotopologues and thus change the stable isotope ratio, which is expressed as

$$
\delta^{13} \mathrm{C}=\left[\frac{\left(\frac{\left[{ }^{13} \mathrm{C}\right]}{\left[{ }^{12} \mathrm{C}\right]}\right)_{\text {sample }}}{\left(\frac{\left.{ }^{13} \mathrm{C}\right]}{\left.{ }^{12} \mathrm{C}\right]}\right)_{\text {standard }}}-1\right]
$$

where measurements are referenced against a standard carbon isotopic ratio, usually VPDB (Vienna Pee Dee Belemnite). Measurements of $\delta^{13} \mathrm{C}$ are commonly multiplied by $1000 \%$ o for readability purposes (Goldstein and Shaw, 2003; Brenninkmeijer, 2009).

Isotopically lighter molecules usually react faster than isotopically heavier ones. In the case of hydrocarbons, this is because bonds in molecules containing solely ${ }^{12} \mathrm{C}$ atoms are weaker than those containing one or more ${ }^{13} \mathrm{C}$ atoms. This causes small deviations from the original ${ }^{13} \mathrm{C} /{ }^{12} \mathrm{C}$ ratio during chemical degradation. The ratio of the two rate coefficients of the different isotopologues is known as a kinetic isotope effect (KIE).

$\mathrm{KIE}=\frac{\mathrm{k}_{12}}{\mathrm{k}_{13}}$.

Knowledge of the KIE of relevant chemical reactions can provide a tool to improve the understanding of hydrocarbon atmospheric processing (Rudolph and Czuba, 2000).

Development of the coupled gas chromatography - (combustion interface) - isotope ratio mass spectrometer (IRMS), as pioneered by Matthews and Hayes (1978) for $\mathrm{CO}_{2}$ and $\mathrm{N}_{2}$ isotope work, substantially improved upon earlier techniques based on dual-inlet isotope ratio mass spectrometers by greatly reducing necessary sample size and eliminating the need to extract individual compounds from a sample, which is a difficult and time-consuming task. This breakthrough allowed significant research work into the stable isotopic ratios of carbon, nitrogen, oxygen and hydrogen containing compounds in the atmosphere.

Development of instrumentation able to accomplish compound specific measurement of carbon isotope ratios of NMHC is somewhat newer (Rudolph et al., 1997; Goldstein and Shaw, 2003; Brenninkmeijer, 2009). Rudolph et al. (1997) developed the first instrument capable of compound specific stable carbon isotope ratio analysis measurements of multiple NMHCs. This instrument was initially used for observing carbon isotope ratios of emissions from biomass burning and transportation related sources, and urban environment atmospheric samples. The observance of the magnitude of the kinetic isotope effect in hydrocarbon reactions with $\mathrm{OH}$ and $\mathrm{O}_{3}$ was also undertaken in subsequent research with this instrument (Rudolph et al., 1997, 2002; Iannone et al., 2003; Anderson et al., 2004).

The availability of such measurements allowed the subsequent development and application of the so-called isotopic hydrocarbon clock approach, which is expressed as follows (Rudolph and Czuba, 2000):

$\delta_{Z}=t_{\mathrm{av}} \cdot{ }^{\mathrm{OH}} \mathrm{k}_{Z} \cdot[\mathrm{OH}] \cdot{ }^{\mathrm{OH}} \mathrm{KIE}_{Z}+{ }^{0} \delta_{Z}$

where $\delta_{Z}$ is the measured isotopic ratio of a compound $Z$, $t_{\mathrm{av}}$ the average age of the air mass, ${ }^{\mathrm{OH}_{\mathrm{k}}} \mathrm{k}$ the rate of reaction of the compound with $\mathrm{OH},[\mathrm{OH}]$ the concentration of $\mathrm{OH},{ }^{\mathrm{OH}} \mathrm{KIE}_{Z}$ the KIE in the reaction of compound $Z$ with $\mathrm{OH}$, and ${ }^{0} \delta_{Z}$ the source isotope ratio of compound $Z$; it may also be further extended by adding terms representing reactions with e.g. $\mathrm{O}_{3}$ or $\mathrm{Cl}$. This approach can improve estimates of compound age compared to previous efforts, which relied on ratios of mixing ratios of two compounds emitted at the same time (Rudolph and Czuba, 2000). In the case of light non-methane hydrocarbons, the relatively short lifetime of these compounds in the atmosphere, from mere hours to tens of days, gives the possibility of utilizing the isotopic hydrocarbon clock approach to constrain transport and aging in the atmosphere (Rudolph and Ehhalt, 1981; Rudolph et al., 2002; Goldstein and Shaw, 2003; Redeker et al., 2007).

Other applications of similar instruments that have been subsequently derived include measurements of NMHC $\delta^{13} \mathrm{C}$ in urban, marine and costal atmospheres and over the north Pacific and east Asia to evaluate atmospheric transport and airmass age (Tsunogai and Yoshida, 1999; Saito et al., 2002, 2009; Nara et al., 2007); of NMHC from biomass burning (Czapiewski et al., 2002; Nara et al., 2006); with some extension, measurements of halocarbons and NMHC (Archbold et al., 2005; Redeker et al., 2007); specific measurement of chloromethane from plants and its atmospheric budget (Bill et al., 2002; Harper et al., 2003; Keppler et al., 2005); and measurement of leaf emissions of acetaldehyde to investigate biochemical reaction pathways (Jardine et al., 2009). Such measurements can be powerful tools to disentangle the relative contribution of different sources to the atmospheric burden of important atmospheric trace gases.

Here we present a new instrument that is capable of highprecision measurements of NMHC stable carbon isotope ratios. It has the unique capacity of being able to process very high volume samples of up to 3001 , such as those necessary for stable carbon isotope measurements of NMHC from very clean samples (e.g. stratospheric, firn air samples, or remote high volume air samples) and the flexibility of accepting samples from many other sources. The system is constructed and tested to analyze $\delta^{13} \mathrm{C}$ of non-methane hydrocarbons from $\mathrm{C}_{2}$ to $\mathrm{C}_{6}$, and methyl chloride.

\section{Experimental}

\subsection{System description and procedure}

\subsubsection{The preconcentration system}

The system (Fig. 1) is largely based on well-established cryotrapping techniques and allows for stable isotope analysis 
of a variety of different samples. All cryotraps were operated at $77 \mathrm{~K}$ and cooled with liquid nitrogen. If not specified otherwise, electrical heating desorbed the trapped compounds. Helium was used as carrier gas to transfer the sample through the different components of the system. To allow the sampling of large volume samples, it is necessary to initially utilize large diameter cryotraps and progressively cryofocus to smaller volumes prior to $\mathrm{GC}$ injection. Cryogenic traps, when implemented properly, do not create isotopic fractionation (Archbold et al., 2005; Redeker et al., 2007). The following parts of the preconcentration system are described below: (i) the primary cryogenic sampling trap (referred to as SAMP trap); (ii) the separation trap to separate $\mathrm{CO}_{2}$ from the NMHCs (referred to as SEP trap); (iii) the W-shaped cryogenic recovery trap (REC trap); and (iv) the final cryogenic focusing trap (FOC trap).

The SAMP trap is a $0.5 \mathrm{~m} \times 4 \mathrm{~mm}$ ID stainless-steel tube filled with 100/120 mesh glass-bead packing material, capable of at least 100 standard $\mathrm{ml} \mathrm{min}^{-1}$ (standard conditions are $0^{\circ} \mathrm{C}, 1$ bar) flow rates without loss. Typically this trap is operated at a flow of 50 standard $\mathrm{ml} \mathrm{min}^{-1}$, which is maintained by a MKS thermal mass flow-controller. A dual-head rotary pump (KNF Neuberger $\mathrm{GmbH}$, Germany) draws the sample through the trap, and provides removal of bulk gases (mainly $\mathrm{N}_{2}$ and $\mathrm{O}_{2}$ ). Desorption of any sample on the trap is accomplished by heating it to $120^{\circ} \mathrm{C}$ within $1 \mathrm{~min}$ after extraction.

The most innovative design feature of the preconcentration system is the method of $\mathrm{CO}_{2}$ removal. Whereas other systems (Rudolph et al., 1997; Tsunogai et al., 1999; Archbold et al., 2005) rely on chemical removal of any $\mathrm{CO}_{2}$ employing Carbosorb, Ascarite II or other sodium hydroxide-on-silica beads, here a packed stainless steel GC-column (Supelco PoraPAK Q, $3 \mathrm{~m} \times 4 \mathrm{~mm}$ ID, 100/120 mesh) acted as a trap for NMHCs and allowed unwanted $\mathrm{CO}_{2}$ to pass. We designed the SEP trap as a non-chemical removal method to ensure effective separation for large samples, i.e. samples with a high $\mathrm{CO}_{2}$ content. $\mathrm{CO}_{2}$ must be removed before IRMS analysis can occur, because the target compounds are oxidized to $\mathrm{CO}_{2}$ for isotope analysis. In order to do so, the sample is injected on this trap at $70 \mathrm{ml} \mathrm{min}{ }^{-1}$ with helium as the carrier gas. The system procedure developed as a result of SEP trap testing (see Sect. 2.1.3, below) reverses the flow through the column after 10 minutes (any $\mathrm{CO}_{2}$ having been vented) to retrieve the compounds of interest from the column at a reduced helium flow rate $\left(11.2 \mathrm{ml} \mathrm{min}^{-1}\right)$. During recovery, the column is heated to and kept at $120^{\circ} \mathrm{C}$ over a period of $40 \mathrm{~min}$

Before the sample material is recovered on the REC trap, any small remnant $\mathrm{CO}_{2}$ and any $\mathrm{H}_{2} \mathrm{O}$ is removed in a small glass reactor containing Ascarite II and $\mathrm{Mg}\left(\mathrm{ClO}_{4}\right)_{2}$. The REC trap is a $0.7 \mathrm{~m} \times 2.5 \mathrm{~mm}$ ID W-shaped stainless steel cryotrap containing 100/120 mesh glass beads. After the recovery time of $40 \mathrm{~min}$, the REC trap is heated to $100^{\circ} \mathrm{C}$, thereby releasing the sample over the course of $5 \mathrm{~min}$ at
Table 1. Mean and standard deviation in $\delta^{13} \mathrm{C}(\%$ ) SEP trap evaluation data.

\begin{tabular}{lllll}
\hline Compound & $\begin{array}{l}\text { No SEP } \\
\text { trap }^{\mathrm{a}} \\
\text { mean } \delta^{13} \mathrm{C}\end{array}$ & $\begin{array}{l}\text { No SEP } \\
\text { trap }^{\mathrm{a}} \\
\sigma \delta^{13} \mathrm{C}\end{array}$ & $\begin{array}{l}\text { Standard } \\
\text { config. } \\
\text { mean } \delta^{13} \mathrm{C}\end{array}$ & $\begin{array}{l}\text { Standard } \\
\text { config. }^{\mathrm{b}} \\
\sigma \delta^{13} \mathrm{C}\end{array}$ \\
\hline Ethane & -28.4 & 0.33 & -28.6 & 0.27 \\
Propane & -34.6 & 0.49 & -34.3 & 0.49 \\
Methyl Chloride & -46.4 & 0.69 & -48.8 & 0.72 \\
Benzene & -27.4 & 0.36 & -27.5 & 0.39 \\
\hline
\end{tabular}

a SEP trap removed from system, $n=10^{\mathrm{b}}$ Standard configuration, SEP trap installed, $n=10$.

$4.1 \mathrm{ml} \mathrm{min}^{-1}$ to the FOC trap, a $0.5 \mathrm{~m} \times 0.25 \mathrm{~mm}$ ID stainless steel-jacketed capillary cryotrap. Sample injection into the GC occurs by extracting and heating the FOC trap to a temperature of over $100^{\circ} \mathrm{C}$ within $30 \mathrm{~s}$, at a flow rate of $2.1 \mathrm{ml} \mathrm{min}^{-1}$.

\subsubsection{SEP trap verification and testing}

Figure 2 displays a total ion abundance chromatogram demonstrating the separation properties of SEP trap under room temperature and aforementioned standard He flow rates

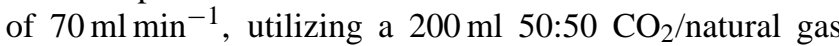
testing mix and a quadrupole mass spectrometer as a detector at the outlet of the SEP trap. Natural gas has a widely varying composition, but generally consists of methane (as bulk gas) and contains significant amounts of nitrogen, $\mathrm{CO}_{2}$, and higher hydrocarbons such as ethane and propane (Škrbiæ and Zlatkoviæ, 1983; Milton et al., 2010). The injected mixture of natural gas and $\mathrm{CO}_{2}$ as chosen here represents a test of separation column performance of a very demanding sample introduced on the system, representing the $\mathrm{CO}_{2}$ content of approximately 3001 of ambient air. Figure 2 shows that at $10 \mathrm{~min}$ after injection the bulk of methane, remnant nitrogen (peak A) and $\mathrm{CO}_{2}$ (peak B), has eluted while ethane and other hydrocarbons (peak C) are still in the SEP trap. Therefore the system procedure has been set to reverse the flow through the column after $10 \mathrm{~min}$ to retrieve the compounds of interest, after venting all $\mathrm{CO}_{2}$.

Further, we performed tests to confirm that the SEP trap has no significant effect on the $\delta^{13} \mathrm{C}$ measurements of the selected hydrocarbons. The tests consisted of 10 measurements of calibration gas (working standard gas, AiR Inc., described further in Sect. 2.2) in two configurations: (i) with the system in standard configuration but the SEP trap short-cut (removed), and (ii) with the system in standard configuration, respectively. Table 1 shows that the means and standard deviations are nearly identical for the hydrocarbons. However, there is a consistent shift $(-2 \%$ ) for methyl chloride, for which a correction is neccessary. A similar effect was noted in Archbold et al. (2005), for chemical removal and adsorbance traps. The cause of this shift is as yet unexplained. 


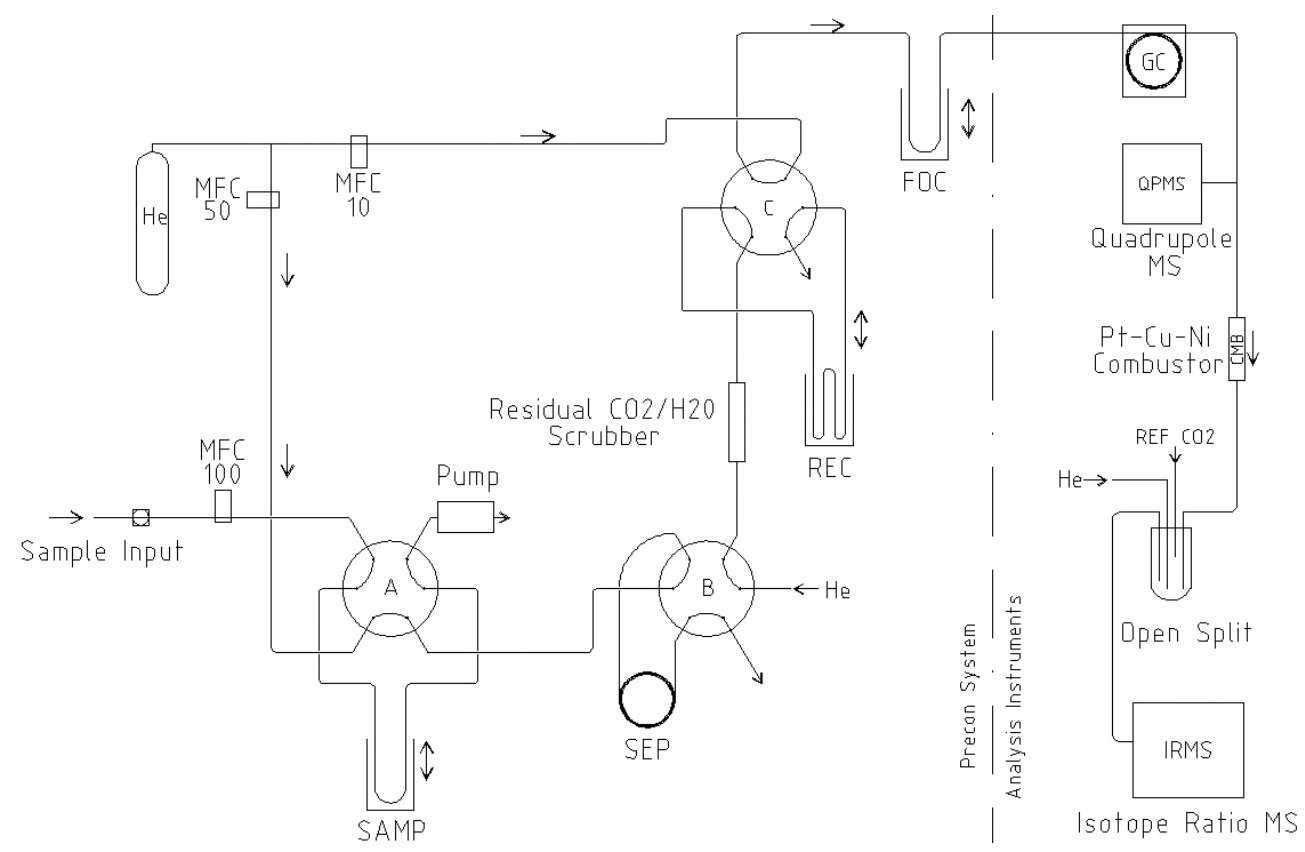

Fig. 1. System diagram. A, B, C indicate Valco 6-port valves; SAMP, SEP, REC, and FOC indicate the primary sampling cryotrap, the separation trap, the recovery cryotrap, and the focusing cryotrap, respectively. Mass flow controller (MFC) maximum flow rates are indicated in units of $\mathrm{ml} \mathrm{min}^{-1}$ (standard conditions).

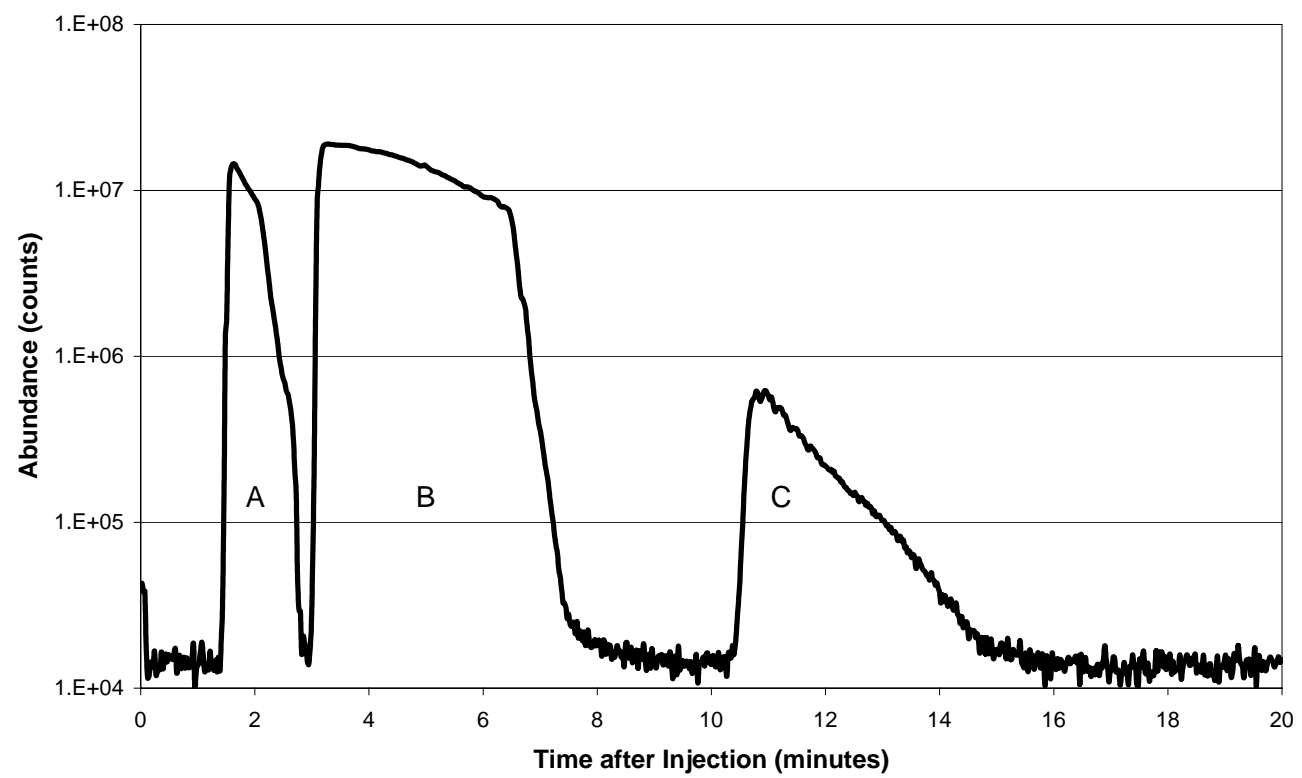

Fig. 2. Performance of the separation trap. The identity of peaks $\mathbf{A}$ (methane and nitrogen), $\mathbf{B}$ (bulk carbon dioxide), and $\mathbf{C}$ (ethane and other hydrocarbons) was confirmed by individual mass signals of the quadrupole mass spectrometer.

\subsubsection{GC separation, combustion and detection}

Gas chromatographic separation is done on a $52.5 \mathrm{~m} \times 0.25 \mathrm{~mm}$ Varian PoraPLOT Q GC column in a HP $5890 \mathrm{GC}$. The column is maintained at $40^{\circ} \mathrm{C}$ for 10 minutes, thereafter being heated at a rate of $12^{\circ} \mathrm{C} \mathrm{min}^{-1}$ to
$240{ }^{\circ} \mathrm{C}$. This temperature is maintained for $35 \mathrm{~min}$, giving a total run time of $65 \mathrm{~min}$. When not in use, the GC oven is maintained at $150{ }^{\circ} \mathrm{C}$. Helium is used as the carrier gas and a constant flow of $2.1 \mathrm{ml} \mathrm{min}^{-1}$ is maintained by a mass flow controller (MKS). 
The effluent from the GC column is roughly split $1: 1$ between a quadrupole mass spectrometer (HP5970) for identification of the compounds, and the remainder sent to a ThermoFinnigan Delta ${ }^{+}$XP IRMS by way of a platinum-coppernickel ceramic combustor (maintained at $900{ }^{\circ} \mathrm{C}$ and restored daily with $\mathrm{O}_{2}$ ), a nafion drier, and an open-split interface (Röckmann et al., 2003). The actual flow into the IRMS is approximately $0.5 \mathrm{ml} \mathrm{min}{ }^{-1}$. IRMS $\delta^{13} \mathrm{C}$ drift is monitored through direct injection of $\mathrm{CO}_{2}$ via the open-split as a working standard. The stable carbon isotope ratio of this $\mathrm{CO}_{2}$ has been calibrated as $-34.0 \% \circ \pm 0.1$ vs. VPDB by Rijksuniversiteit Groningen, The Netherlands. Mixing ratios are calculated from the IRMS $m / z 44$ peak area measurements of each peak in the chromatogram, relative to peak areas from the working standard gas at accuracy levels of $\pm 10 \%$ (see below). Mixing ratios of compounds not contained in the regularly measured working standard gas were estimated by extrapolation based on the number of carbon atoms in the molecules of the species in question and can therefore contain a larger systematic error $( \pm 30 \%) . \delta^{13} \mathrm{C}$ values are calculated from the individual ion signals of the IRMS, integrated per trace $(\mathrm{m} / \mathrm{z}, 44,45,46$; automatic peak detection under normal operation, manual evaluation if necessary), and mathematically corrected for ${ }^{17} \mathrm{O}$ through the ISODAT isotope ratio analysis package, utilizing the correction from Santrock et al. (1985).

The sample chromatograms shown in Fig. 3 show the IRMS intensity traces at $\mathrm{m} / \mathrm{z} 44$ of two gas standards and an ambient air sample; and a 44/45 ratio trace for that ambient air sample, respectively, thus demonstrating the separation performance of the GC-IRMS system.

\subsubsection{Ambient air sampling unit}

As an addition to the basic system described above, a highflow sampling unit (diagram Fig. 4) was developed allowing ambient air sampling at rates of up to $11 \mathrm{~min}^{-1}$. The unit is set up as an auxiliary 2-stage cryogenic trapping system consisting of a large diameter stainless steel water trap $(0.25 \mathrm{~m} \times 2.1 \mathrm{~cm}$ ID) and a stainless steel U-trap $(0.5 \mathrm{~m} \times 1.0 \mathrm{~cm}$ ID) filled with glass beads $(80 / 100 \mathrm{mesh})$. The water trap is constructed of $2.54 \mathrm{~cm}$ tubular stainless steel with large diameter Swagelok fittings and $0.32 \mathrm{~cm}$ (ID) stainless steel lines. The internal volume of this trap (approximately $100 \mathrm{ml}$ ) is large enough to freeze out water vapor from very large and humid air samples.

Sampling proceeds as follows: both traps are immersed in liquid nitrogen while flush gas (ultra pure synthetic air or nitrogen) is drawn through the system at $50 \mathrm{ml} \mathrm{min}^{-1}$ by a dual head high-flow rotary pump downstream of the traps. The use of a pump keeps pressure inside the traps low at all times to prevent the condensation of oxygen. Once both traps are at temperature (approximately $2 \mathrm{~min}$ ), the synthetic air supply is closed, the ambient sample line valve is opened, flow rates are increased to $0.5-11 \mathrm{~min}^{-1}$ and sampling be- gins. Following the sampling of the desired volume, the flow rate is reduced to $50 \mathrm{ml} \mathrm{min}^{-1}$, the sampling valve is closed, and the flush gas is reintroduced. Subsequently the pump valve is closed and the valve to the preconcentration system is opened and the traps are extracted from the liquid nitrogen in turn: first the water trap is removed and left to warm in laboratory ambient air for $5 \mathrm{~min}$ to reduce pressure effects from rapid warm up of such a large volume. Then it is inserted in a warm water bath at $40^{\circ} \mathrm{C}$ to release adsorbed volatiles, while retaining water in liquid form at the bottom of the trap. The liberated volatiles are transferred to the large diameter $\mathrm{U}$ trap over $5 \mathrm{~min}$. This trap is then extracted from the liquid nitrogen and allowed to warm in ambient laboratory air over $5 \mathrm{~min}$, and is subsequently heated out under a $500^{\circ} \mathrm{C}$ air stream for $5 \mathrm{~min}$ to transfer all sampled compounds to the preconcentration system.

\subsubsection{Automatization}

With the exception of the ambient air sampling unit, the system has fully automatic operation. Pneumatic lifters are used to move the traps in or out the Dewar vessels filled with liquid nitrogen. The traps, flow controllers, and valves are operated electronically via a process/time table. Autonomous operation is limited to about $10 \mathrm{~h}$ by the supply of liquid nitrogen in the Dewar vessels.

\subsection{Performance and stability}

For calibration, a 9-compound reference gas (Apel-Riemer, AiR Environmental, Inc.) is used as the primary working standard. Of the compounds in this gas, 4 are monitored in test and calibration runs at the start and end of each measuring day, and during night (automated), namely ethane (206 ppb), propane (103 ppb), methyl chloride (103 ppb) and benzene (103 ppb). Calibration runs with the standard were done with varying volumes, either 50,100 , or $200 \mathrm{ml}$, to ensure a range of peak areas similar to results in sample measurements and to test for non-linearity effects. Calibation runs using $100 \mathrm{ml}$ of this gas were most commonly done. Usage of low volume high concentration calibration gas as compared to a high volume dilution of the same was found to have no effect in calibration results, similar to previous research (e.g. Archbold et al., 2005; Redeker et al., 2007), further verifying trap performance.

The $\delta^{13} \mathrm{C}$ values of propane, methyl chloride, and benzene in the working standard were established utilizing the method described in Fisseha et al. (2009), at the Forschungszentrum Jülich, Germany, to be $-34.8 \pm 0.4,-48.7 \pm 0.4$, and $-28.1 \pm 0.3 \%$ vs. VPDB, respectively. These calibration results agree ( \pm 0.3 to $\pm 0.8 \%$, depending on compound) with all measurements of these compounds obtained by our system when calibrated against the aforementioned injected $\mathrm{CO}_{2}$, and taking into account the shift in methyl chloride. Unfortunately, no independent measurement of ethane was achieved by the Jülich group. However, calibration results of 


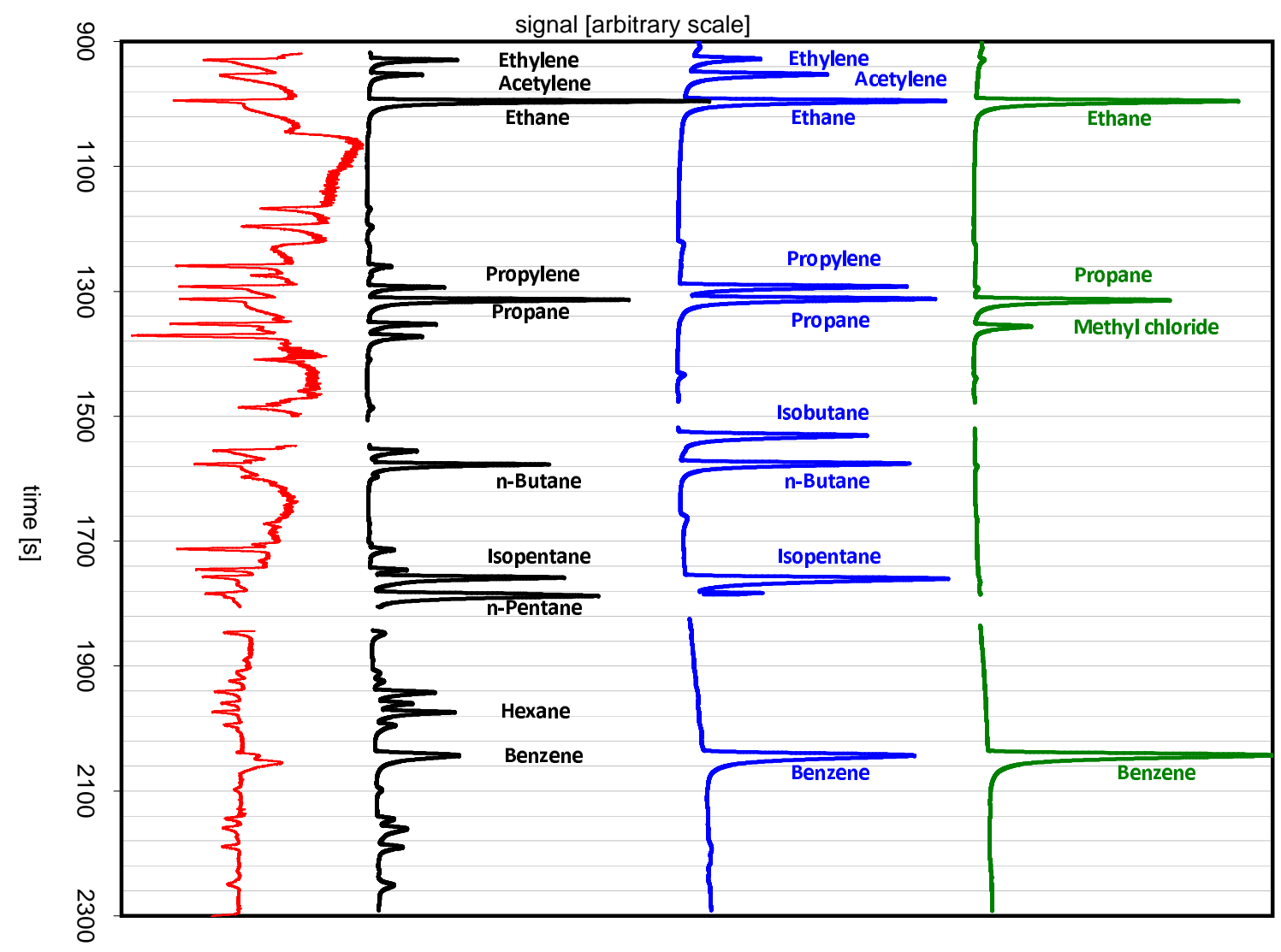

Fig. 3. Example chromatograms (IRMS, $m / z 44$ signal) of the working gas standard (green trace), the second calibration gas standard (blue trace), and an ambient air sample (black trace), respectively. Peak identification of the ambient sample is based on retention time and the mass spectrum obtained with the quadrupole mass spectrometer. Additionally, the ambient air sample 44/45 ratio trace is provided (red trace) to demonstrate peak separation.

the other tested gases and the reference $\mathrm{CO}_{2}$ give high confidence that our estimate of $-28.6 \pm 0.4 \%$ vs. VPDB is valid for ethane.

If the peak area of a given eluted compound was maintained above $0.5 \mathrm{Vs}$, the IRMS measured $\delta^{13} \mathrm{C}$ values showed no dependency on the sample size. Below this value peak integration can yield inaccurate results and therefore a signal of $0.5 \mathrm{Vs}$ was considered the limit of detection.

Figure 5 shows time series of $\delta^{13} \mathrm{C}(\% \circ)$ and system sensitivity to illustrate the long term stability of the system in the current configuration (since May 2009). The sensitivity was typically in the range $0.2-0.32 \mathrm{Vs} \mathrm{ngC}^{-1}$. Some variability is evident from Fig. $5 \mathrm{~b}$ and can be attributed to the internal variability of the filament emission in the IRMS. This variation is taken into account by referencing against the aforementioned gas standard. Repeatability of mixing ratio measurements is evaluated to be less than $\pm 5 \%$ for all compounds. Together with the specified accuracy of $\pm 5 \%$ for the gas standard this defines the overall error of $\pm 10 \%$ for measured mixing ratios. The detection limit in terms of collected amount of carbon is calculated to be $1.5-2.5 \mathrm{ngC}$, based on the limit of $0.5 \mathrm{Vs}$ for the IRMS signal and the observed sensitivity range. Figure 5a illustrates also a drift of $\delta^{13} \mathrm{C}$ in the system over the selected period. In order to correct for drift in $\delta^{13} \mathrm{C}$, detrending is accomplished by observing weekly averages as compared to long-term calibration measurement means.

To evaluate the overall precision of the system a series of Gaussian-fitted histograms of detrended $\delta^{13} \mathrm{C}$ for the compounds measured in the standard gas are provided in Fig. 6a$\mathrm{d}$, with a bin size of $0.1 \%$, outliers greater than $3 \sigma$ rejected. For ethane, propane and benzene the 1- $\sigma$ error was below $0.5 \%$ for all volumes tested. For methyl chloride, the standard deviation is $\sim 0.8 \%$ o for all tested volumes. These values are based on the entire dataset. The same analysis based on sub-samples including only the 50,100 , or $200 \mathrm{ml}$ measurements yield very similar results. For example, for ethane, the mean $\delta^{13} \mathrm{C}$ is $-28.9,-28.9,-28.6$ and $-28.9 \%$, for 50 , $100,200 \mathrm{ml}$ data, and all data, respectively; the corresponding standard deviations are $0.308,0.296,0.205$, and $0.284 \%$ o. These values show that the sample volume does not influence the measurements. For other tested compounds, behavior is similar. 


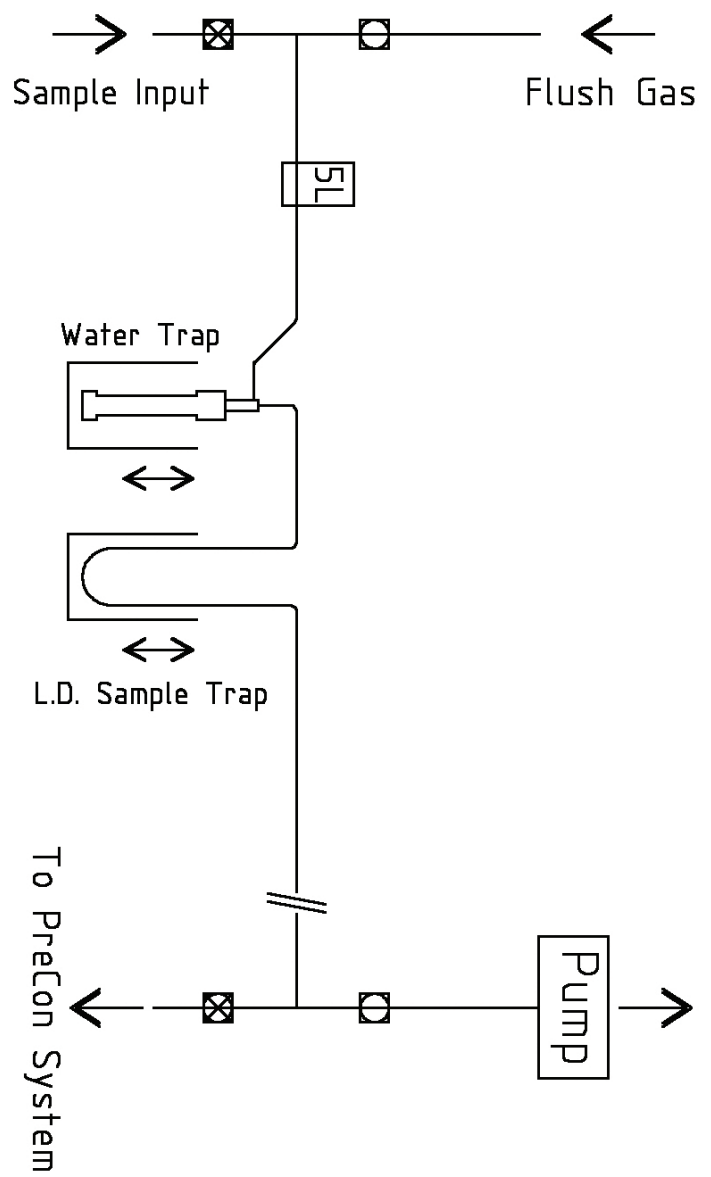

Fig. 4. Ambient air sampling unit. The water trap and the sample trap are large diameter cryogenic stainless steel traps. Flush gas may be $\mathrm{He}, \mathrm{N}_{2}$ or synthetic air. Flows are regulated by a $51 \mathrm{~min}^{-1}$ mass flow controller (MKS instruments). After extraction, the contents of the sample trap are flushed to the preconcentration system (Fig. 1).

The reproducibility for other compounds was tested by introducing another standard gas, containing 20 to $50 \mathrm{ppb}$ of acetylene, ethylene, propylene and $\mathrm{C}_{4}$ and $\mathrm{C}_{5}$ saturated hydrocarbons (also see Fig. 3). The results of stability evaluations of these compounds are broadly similar to those of the primary working standard. Table 2 summarizes $\delta^{13} \mathrm{C}$ and sensitivity means and $1-\sigma$ errors of all tested compounds.

\section{First results}

To demonstrate capabilities of this instrument, we present the results of a 48-h measurement campaign of selected nonmethane hydrocarbons undertaken over 4-6 August 2009. Samples were taken from an ambient air inlet located $\sim 20 \mathrm{~m}$ above ground level at $52^{\circ} 05^{\prime} 14^{\prime \prime} \mathrm{N}, 5^{\circ} 09^{\prime} 57^{\prime \prime} \mathrm{E}$. The sampling location is within $500 \mathrm{~m}$ of a traffic highway, and is located outside our laboratory on the Utrecht University campus, in a semi-urban environment. Thus, an abundance of
Table 2. Means and $1-\sigma$ standard deviations of $\delta^{13} \mathrm{C}(\%)$ and IRMS Sensitivity (Vs ngC ${ }^{-1}$ ) for compounds in regularly used calibration gases.

\begin{tabular}{lll}
\hline Compound & $\begin{array}{l}\delta^{13} \mathrm{C} \text { mean } \\
\pm \sigma(\%)\end{array}$ & $\begin{array}{l}\text { Sensitivity mean } \\
\pm \sigma\left(\mathrm{Vs} \mathrm{ngC}^{-1}\right)\end{array}$ \\
\hline & \multicolumn{2}{c}{ Primary NMHC working standard } \\
\hline Ethane & $-28.898 \pm 0.284$ & $0.249 \pm 0.0053$ \\
Propane & $-34.716 \pm 0.397$ & $0.254 \pm 0.0063$ \\
$\mathrm{MeCl}$ & $-48.528 \pm 0.795$ & $0.231 \pm 0.0058$ \\
Benzene & $-27.915 \pm 0.484$ & $0.302 \pm 0.0083$ \\
\hline \multicolumn{3}{c}{ Other tested compounds ${ }^{\mathrm{b}}$} \\
\hline Acetylene & $-40.922 \pm 0.441$ & $0.241 \pm 0.0062$ \\
Ethylene & $-36.307 \pm 0.716$ & $0.239 \pm 0.010$ \\
Propylene & $-32.955 \pm 0.658$ & $0.258 \pm 0.010$ \\
Isobutane & $-32.209 \pm 0.542$ & $0.271 \pm 0.0097$ \\
Butane & $-35.658 \pm 0.476$ & $0.273 \pm 0.0083$ \\
Isopentane & $-34.927 \pm 0.308$ & $0.33 \pm 0.0095$ \\
\hline
\end{tabular}

a 9-month detrended long-term accuracy levels ${ }^{\mathrm{b}} n=20$, over period of 1 month.

local sources, dominated by traffic emissions, can be expected for hydrocarbons. Atmospheric conditions at the time of the campaign were characterized by warm stable summer weather. During this period, high surface pressure was located above the North Sea. The sample days were similar meteorologically, with clear skies, light winds, and high temperatures near $30^{\circ} \mathrm{C}$. At night, temperatures decreased to near $20^{\circ} \mathrm{C}$ and the winds became near calm.

The samples were taken and processed in situ using the aforementioned ambient sampling unit, with 201 samples (sampling rate $0.51 \mathrm{~min}^{-1}$ ) taken at approximately 2 -h intervals (excepting necessary calibration runs of the instrument) and processed immediately. The short time interval between samples afforded by the instrument design allowed detailed insight into diurnal evolution of $\mathrm{NMHC} \delta^{13} \mathrm{C}$; more so than the majority of previous urban stable carbon isotope studies. The 201 sample size was chosen to ensure IRMS peak areas of $>0.5 \mathrm{Vs}$ for the all hydrocarbons of interest.

\subsection{Mixing ratio}

Broadly, mixing ratios are in line with what may be expected for an urban environment (e.g. Seinfeld and Pandis, 1998), although for some compounds, especially the alkanes, quite high mixing ratios of several ppb were measured. The mixing ratios (Fig. $7 \mathrm{a}-\mathrm{j}$ and Table 3 ) show a clear diurnal cycle, which corresponds very well to patterns of urban activity. The unsaturated compounds (acetylene, ethylene, and propylene) exhibit a peak in the morning hours, minimum values in the afternoon, and elevated values at night. Such diurnal cycles agree well with traffic patterns and the development 
A
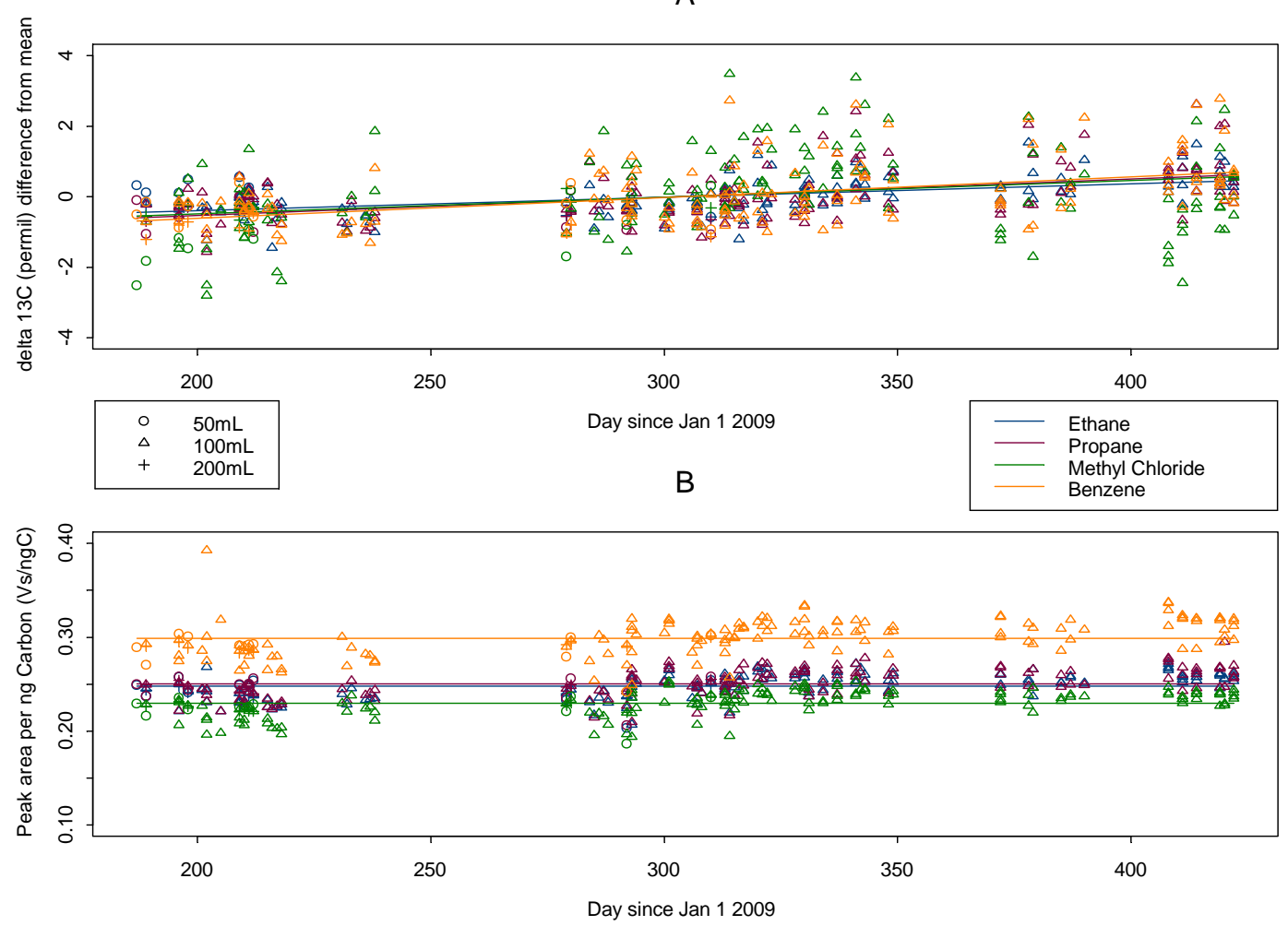

Fig. 5. Time-stability of the system. Panels $\mathbf{A}$ and $\mathbf{B}$ show the difference from mean of $\delta^{13} \mathbf{C}$ (\%o, panel A); and sensitivity (Vs ngC ${ }^{-1}$, panel B) of the 4 tested compounds in the working gas standard, respectively. Data of various injection volumes (50, 100, and 200 ml) are plotted. The lines in panel A represent linear fits; the horizontal lines in panel $\mathbf{B}$ do not represent any trend but are plotted to make the long term variability more visible.

of the boundary layer mixing height. Morning vehicular traffic is intense; heavy congestion on local highways is common in the periods from 07:00 to 09:00 (all times in Central European Summer Time). The afternoon-evening (16:00 to 18:00) peak of traffic, though generally less intense than that of the morning but still notable, is not clearly observed in the data. This is attributed to increased mixing in the afternoon due to the breakup of the nighttime boundary layer, as compared to the morning hours.

Ethane also displays a clear diurnal cycle, but in contrast to the above compounds has peaks in mixing ratio during the night and early morning, far earlier than other compounds. The prevailing meteorological conditions of (near) calm winds during night suppressed mixing and allowed the buildup of continuously emitted gasses. Presuming that the main urban source of ethane is leakage of natural gas, local leakage could cause such an increase of mixing ratio. The daytime decrease may be similarly ascribed to the increase in mixing and dilution.

Isopentane, hexane, and benzene show profiles similar to the unsaturated hydrocarbons mentioned above. The change in mixing during daytime and nighttime can help to explain the afternoon decrease and nighttime buildup in mixing ra- tio of all alkanes measured, with the exception of n-pentane (Fig. 7h), which exhibits larger daytime than night-time mixing ratios. This implies a different, non-local source that dominates the mixing ratios for this compound. Supporting evidence for a distinct and non-local source can be found in the stable isotope measurements of this compound, of which discussion follows.

\subsection{Stable carbon isotope composition}

Figure 8a-j shows $\delta^{13} \mathrm{C}$ measurements over the sampling period. In general, $\delta^{13} \mathrm{C}$ averages over the 48 -h period (Table 4) agree well with published values from studies of urban air.

Acetylene has a large daily variation (maximum of $5 \% 0$ and minimum of $-15 \%$ ), but its mean over the entire period is $-9.1 \%$, which falls well in the urban range of $-8 \pm 4 \%$ o as reported in Goldstein and Shaw (2003). The maximum observed in acetylene is more enriched than previous measurements reported in urban environments, but is within the range of daytime summer values reported from rural/marine environments (Redeker et al., 2007).

Ethylene, which shows a very well defined diurnal cycle with minima near $-30 \%$ in the early morning hours and maxima near $-5 \%$ during the afternoon $(24 \mathrm{~h}$ mean 
A) Ethane

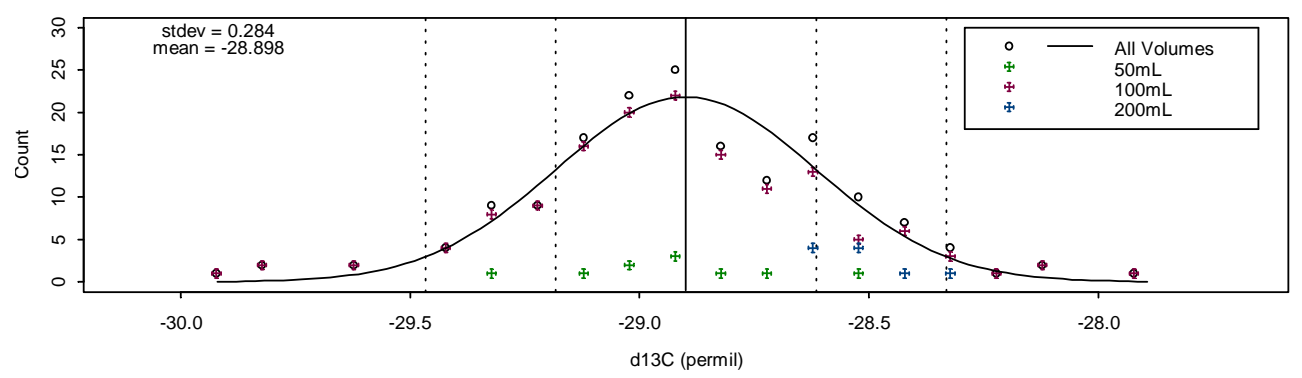

B) Propane

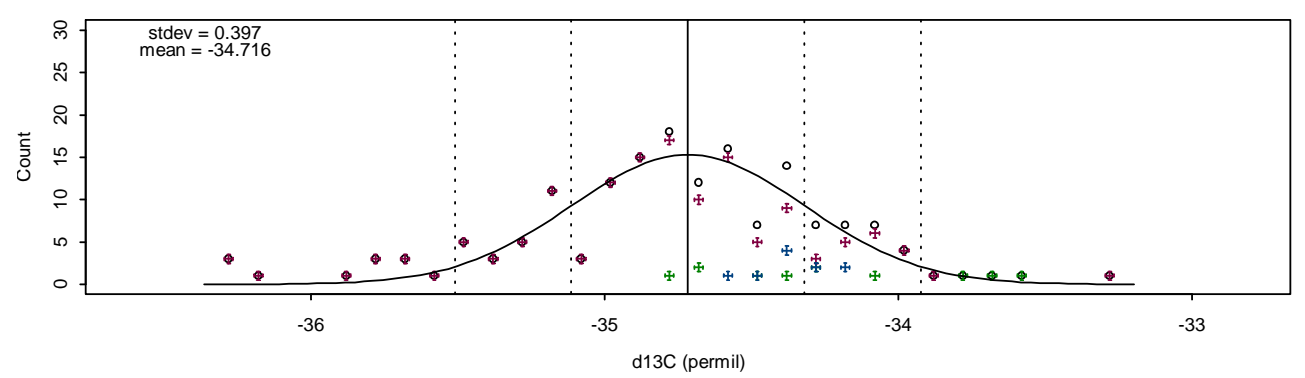

C) Methyl Chloride

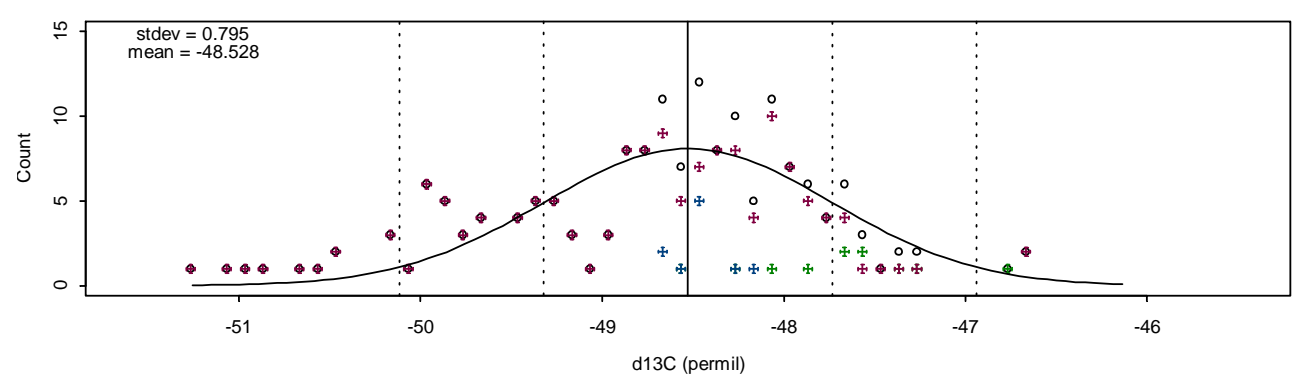

D) Benzene

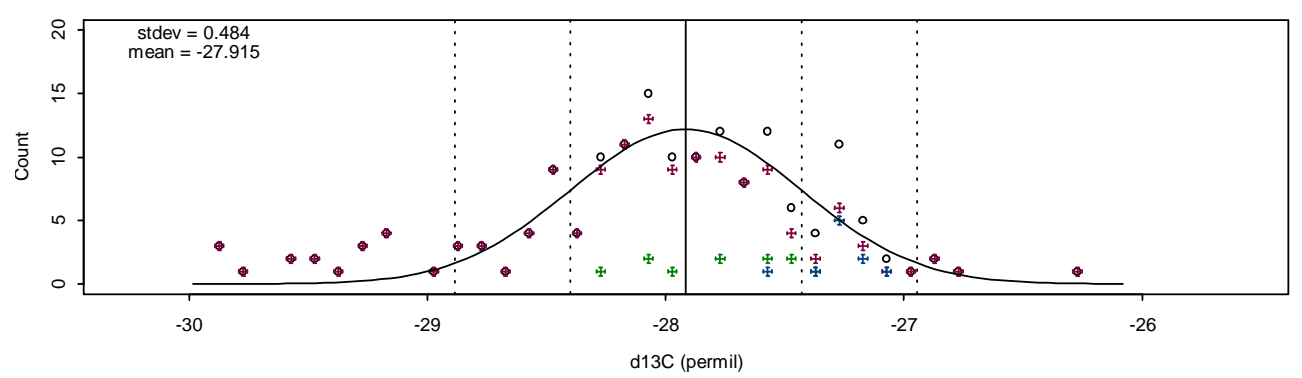

Fig. 6. Histograms of detrended $\delta^{13} \mathrm{C}(\%$ ) data, together with Gaussian fit for the Apel-Riemer (AiR) multicompound NMHC calibration gas, including measurements of various volumes $(50,100,200 \mathrm{ml})$ for peak area ranges comparable to measurements. Dashed lines indicate 1 and $2 \sigma$ intervals.

$-17 \%$ o), agrees with expected mean values for $\mathrm{C}_{2}$ to $\mathrm{C}_{5}$ alkenes $(-22 \pm 8 \%$, Goldstein and Shaw, 2003). The large diurnal variation, can be expected for such a reactive compound with a high KIE (18.6\%o, Anderson et al., 2004). Strong fractionation occurs during summer daylight hours when $\mathrm{OH}$ levels are considerably high. Utilizing the isotopic clock parameterization (Eq. 4, Rudolph and Czuba, 2000) provides additional support for this: assuming that the nighttime $\delta^{13} \mathrm{C}$ value (mean -27\%o) and daytime value (mean $-10 \%$ ) represent the unoxidized $\left({ }^{0} \delta_{\mathrm{C} 2 \mathrm{H} 4}\right)$ and oxidized $\left(\delta_{\mathrm{C} 2 \mathrm{H} 4}\right)$ isotope ratios of ethylene, respectively, a value for ${ }^{\mathrm{OH}_{\mathrm{KIE}} 2 \mathrm{H} 4}$ of $18.6 \%$ and $\mathrm{OH}_{\mathrm{K}_{\mathrm{CH}} 4}=7.9 \times 10^{-12} \mathrm{~cm}^{3} \mathrm{~s}^{-1}$ (at $296 \mathrm{~K}$, Atkinson et al., 2006), it is calculated that $[\mathrm{OH}]$ required for causing this 

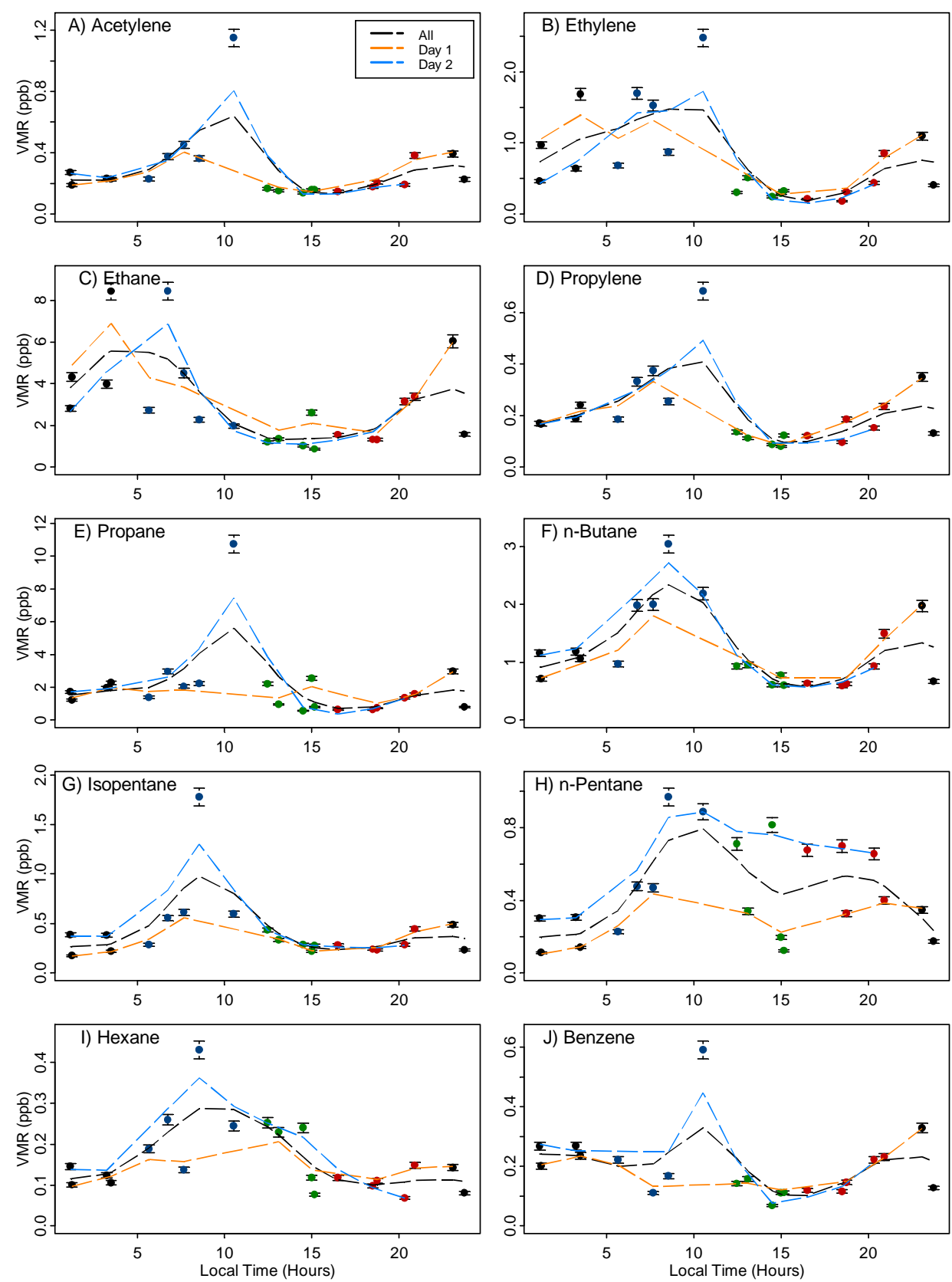

Fig. 7. Mixing ratios (ppb) versus time over 48-h (4-6 August 2009) period, overlapped on one diurnal cycle. Error bars indicate the 10\% accuracy levels. Period means in Table 3. Colors indicate time periods: P1 (black): 21:00-05:00; P2 (blue): 05:00-11:00; P3 (green): 11:0015: 30; P4 (red): 15:30-21:00; these correspond to time period colors in Figs. 8 and 9. Period codes correspond to those in Tables 3, 4, and 5 . Dashed lines are running averages.

fractionation is $3.6 \times 10^{6}$ molecules $\mathrm{cm}^{-3}$ for a $9 \mathrm{~h}$ atmospheric processing time. This $\mathrm{OH}$ concentration is well within the range for summer tropospheric conditions (e.g., Lu and Khalil, 1991).

The ethane stable isotope ratios we measured are in general more enriched than higher alkanes. This is due to its differing source from natural gas, the ethane in which is known to be relatively enriched. The mean $\delta^{13} \mathrm{C}$ of ethane was mea- sured to be $-24.5 \pm 0.6 \%$ of the entire period. Tsunogai and Yoshida (1999) reported values between -28 to $-22 \%$ o in urban and marine locations. There is almost no diurnal variation in our measurements (with the exception of a slight depletion during the period of highest mixing ratio values, in the morning), which is also reasonable to expect for the most stable and longest-lived non-methane hydrocarbon. 
Table 3. Mean mixing ratio and sample standard deviation, 48-h measurements, 4 to 6 August 2009.

\begin{tabular}{|c|c|c|c|c|c|c|c|c|c|c|}
\hline Compound & $\begin{array}{r}\text { Mean VMR } \\
\text { all (ppbv) }\end{array}$ & $\begin{array}{r}\sigma \\
(\mathrm{ppbv})\end{array}$ & $\begin{array}{r}\text { Mean VMR } \\
\mathrm{P}^{\mathrm{a}}(\mathrm{ppbv})\end{array}$ & $\begin{array}{r}\sigma \\
(\mathrm{ppbv})\end{array}$ & $\begin{array}{r}\text { Mean VMR } \\
\text { P2 (ppbv) }\end{array}$ & $\begin{array}{r}\sigma \\
(\mathrm{ppbv})\end{array}$ & $\begin{array}{r}\text { Mean VMR } \\
\text { P3 (ppbv) }\end{array}$ & $\begin{array}{r}\sigma \\
(\mathrm{ppbv})\end{array}$ & $\begin{array}{r}\text { Mean VMR } \\
\text { P4 (ppbv) }\end{array}$ & $\begin{array}{r}\sigma \\
(\mathrm{ppbv})\end{array}$ \\
\hline Acetylene & 0.29 & 0.22 & 0.26 & 0.07 & 0.51 & 0.36 & 0.15 & 0.01 & 0.22 & 0.09 \\
\hline Ethylene & 0.77 & 0.62 & 0.88 & 0.48 & 1.45 & 0.71 & 0.33 & 0.10 & 0.40 & 0.27 \\
\hline Ethane & 3.09 & 2.23 & 4.52 & 2.43 & 3.98 & 2.68 & 1.41 & 0.69 & 2.14 & 1.03 \\
\hline Propylene & 0.21 & 0.14 & 0.21 & 0.08 & 0.36 & 0.19 & 0.11 & 0.02 & 0.16 & 0.05 \\
\hline Propane & 2.02 & 2.14 & 1.83 & 0.77 & 3.87 & 3.88 & 1.41 & 0.90 & 0.99 & 0.45 \\
\hline n-Butane & 1.19 & 0.67 & 1.13 & 0.47 & 2.03 & 0.74 & 0.77 & 0.17 & 0.85 & 0.38 \\
\hline Isopentane & 0.42 & 0.34 & 0.31 & 0.12 & 0.76 & 0.58 & 0.31 & 0.08 & 0.30 & 0.09 \\
\hline n-Pentane & 0.45 & 0.27 & 0.23 & 0.10 & 0.61 & 0.31 & 0.43 & 0.30 & 0.55 & 0.17 \\
\hline Hexane & 0.16 & 0.09 & 0.12 & 0.03 & 0.25 & 0.11 & 0.18 & 0.08 & 0.11 & 0.03 \\
\hline Benzene & 0.20 & 0.11 & 0.24 & 0.07 & 0.27 & 0.21 & 0.12 & 0.03 & 0.17 & 0.06 \\
\hline
\end{tabular}

a Period codes are the same as those defined in Fig. 7.

Table 4. Mean $\delta^{13} \mathrm{C}(\%$ ) vs. VPDB and sample standard deviation, 48-h measurements, 4 to 6 August 2009.

\begin{tabular}{lrrrrrrrrrr}
\hline Compound & $\begin{array}{r}\text { Mean } \delta^{13} \mathrm{C} \\
(\% \circ) \text { all }\end{array}$ & $\begin{array}{r}\sigma \\
(\%)\end{array}$ & $\begin{array}{r}\text { Mean } \delta^{13} \mathrm{C} \\
\mathrm{P} 1^{\mathrm{a}}(\% \circ)\end{array}$ & $\begin{array}{r}\sigma \\
(\% \circ)\end{array}$ & $\begin{array}{r}\text { Mean } \delta^{13} \mathrm{C} \\
\mathrm{P} 2(\% \circ)\end{array}$ & $\begin{array}{r}\sigma \\
(\% \circ)\end{array}$ & $\begin{array}{r}\text { Mean } \delta^{13} \mathrm{C} \\
\mathrm{P} 3(\% o)\end{array}$ & $\begin{array}{r}\sigma \\
(\% o)\end{array}$ & $\begin{array}{r}\text { Mean } \delta^{13} \mathrm{C} \\
\mathrm{P} 4(\% \circ)\end{array}$ & $\begin{array}{r}\sigma \\
(\% \circ)\end{array}$ \\
\hline Acetylene & -9.1 & 4.4 & -10.2 & 1.4 & -10.2 & 4.8 & -6.2 & 6.8 & -9.6 & 2.8 \\
Ethylene & -17.0 & 7.9 & -23.3 & 3.2 & -21.5 & 5.3 & -9.1 & 4.2 & -11.7 & 6.1 \\
Ethane & -24.5 & 0.6 & -24.1 & 0.5 & -24.6 & 0.8 & -24.6 & 0.8 & -24.6 & 0.17 \\
Propylene & -21.1 & 2.3 & -21.7 & 1.3 & -19.6 & 2.5 & -20.3 & 2.5 & -22.8 & 2.1 \\
Propane & -27.9 & 1.7 & -27.0 & 2.3 & -27.8 & 1.4 & -28.6 & 1.7 & -28.3 & 1.1 \\
n-Butane & -27.6 & 1.7 & -27.0 & 1.4 & -26.2 & 1.3 & -29.3 & 1.3 & -27.8 & 1.1 \\
Isopentane & -29.0 & 0.6 & -29.0 & 0.8 & -29.0 & 0.6 & -29.4 & 0.6 & -28.9 & 0.3 \\
n-Pentane & -27.0 & 1.6 & -28.0 & 1.2 & -28.2 & 0.9 & -26.0 & 2.0 & -25.8 & 0.4 \\
Hexane & -30.4 & 3.7 & -28.6 & 1.7 & -32.1 & 7.4 & -29.4 & 1.0 & -30.7 & 1.0 \\
Benzene & -26.2 & 2.3 & -25.9 & 1.4 & -26.8 & 5.1 & -25.5 & 1.6 & -26.7 & 0.2 \\
\hline
\end{tabular}

a Periods are the same as in Table 3.

The $\delta^{13} \mathrm{C}$ of the $\mathrm{C}_{3}$ to $\mathrm{C}_{6}$ alkanes (with the exception of $\mathrm{n}$ butane and n-pentane, see below) show little (clearly apparent) diurnal variation and mean values of -27 to $-30 \%$ during all periods. Previously reported measurements indicated $-27 \pm 2.5 \%$ o (Rudolph et al., 2002; Goldstein and Shaw, 2003). The presence of a single very depleted point (-45\%o) in measurements of hexane is notable, but this outlier may be due to an unidentified experimental problem. Apart from this point, standard deviations for these compounds also correspond well to previous results. Benzene also fits well to previous measurements despite some apparent high morning variability: mean $-26.2 \pm 2.3 \%$, compared to literature values of $-27 \pm 2 \%$ (Goldstein and Shaw, 2003).

\subsection{Source signatures}

A common tool for atmospheric isotope research to decipher sources is the Keeling plot analysis, which was first developed for the analysis of stable carbon isotopes of carbon dioxide (Keeling, 1958). This involves correlating $\delta^{13} \mathrm{C}$ against the inverse of the mixing ratio, and linearly fit- ting the result. The $y$-intercept of this fit then indicates the isotopic composition of the contaminating source that mixes into background air. This procedure is based on a few assumptions, most importantly: (1) there should be only one source and a stable reservoir into which it is being diluted; and (2) the $\delta^{13} \mathrm{C}$ and inverse mixing ratio should be well-correlated; lest the values calculated become unclear and unreliable (Keeling, 1958). In our dataset, the Keeling plot analysis works well for ethylene, n-butane, and npentane (Fig. 9a-c). The isotope source signatures determined this way are given in Table 5. Other measured compounds are not included because of small isotopic variation or low correlation, indicating that the above conditions are violated.

For ethylene the source signatures $(\sim-27 \%)$ derived from this analysis agree well with engine emission measurements (Rudolph et al., 2002; Goldstein and Shaw, 2003). The positive slopes of the Keeling fits are in line with the interpretation of the diurnal variation of the VMR and $\delta^{13} \mathrm{C}$ (see discussion above). 

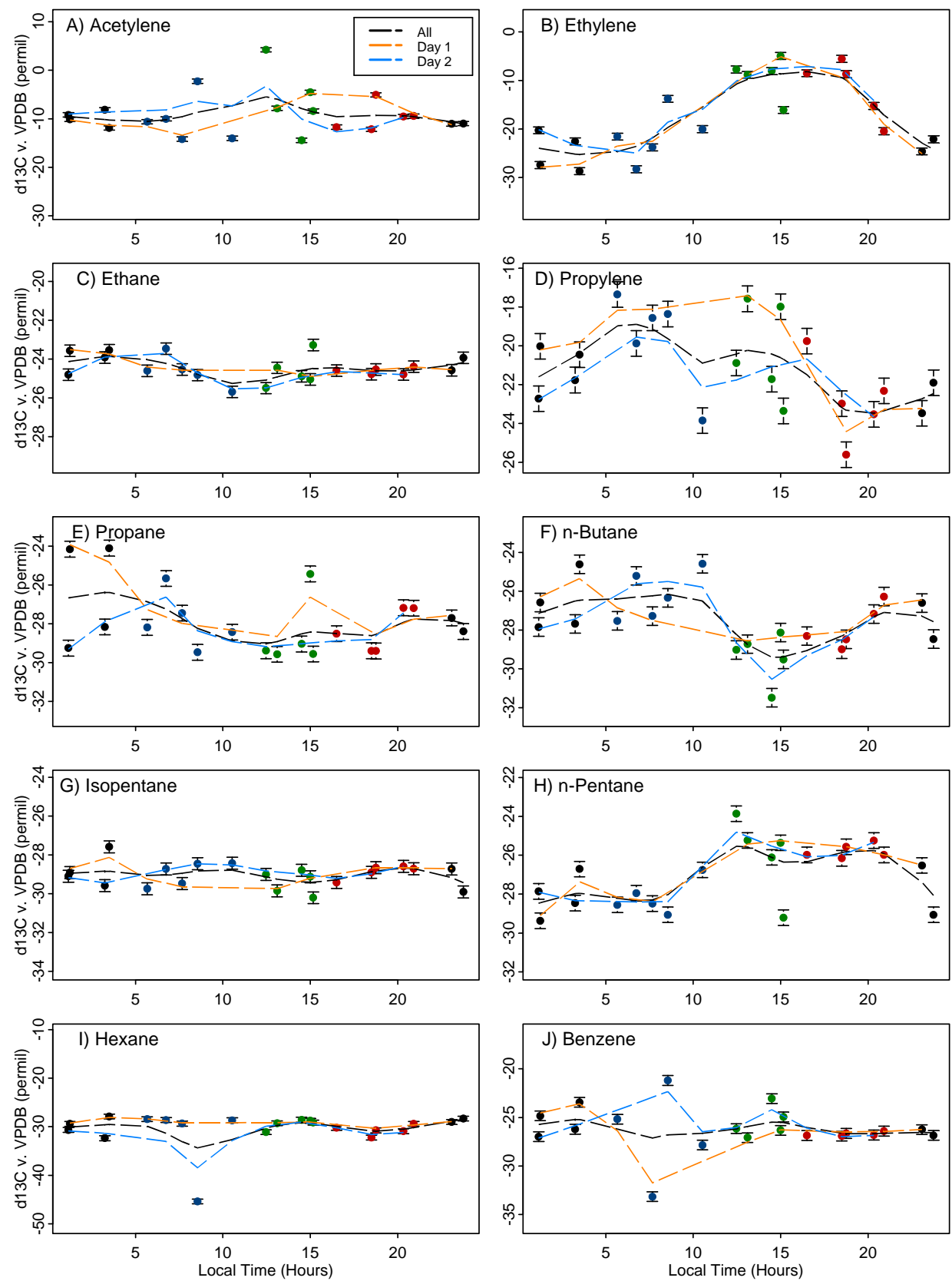

Fig. 8. Compound $\delta^{13} \mathrm{C}$ (\%o vs. VPDB) vs. time (hours) over 48-h (4-6 August 2009) period, overlapped. Error bars indicate 1- $\sigma$ ranges. Period means and standard deviations in Table 4. Colors of points denote the time periods, which are defined in Fig. 7.

The interpretation for $\mathrm{n}$-butane and $\mathrm{n}$-pentane is more complicated because their lifetimes are longer. As a result their mixing ratios are controlled by transport and mixing of different sources. The source signatures of $n$ butane during periods 3 and $4(-25.4$ and $-24.5 \%$, respectively) suggest that emissions from fossil fuel combustion $(-27 \pm 2.5 \%$, Goldstein and Shaw, 2003) are the dominant local source. However, the reversed slope may indicate that background concentrations of n-butane originate mainly from other sources.
In n-pentane there is a strong departure in source signature values in table 5 period 3: here a strongly correlated source signature of $-23.9 \%$ occurs, as compared to more depleted values at other times. This would lend support to the speculation that there is a distinct isotopically different emission occurring at this time as discussed above for the mixing ratios. 

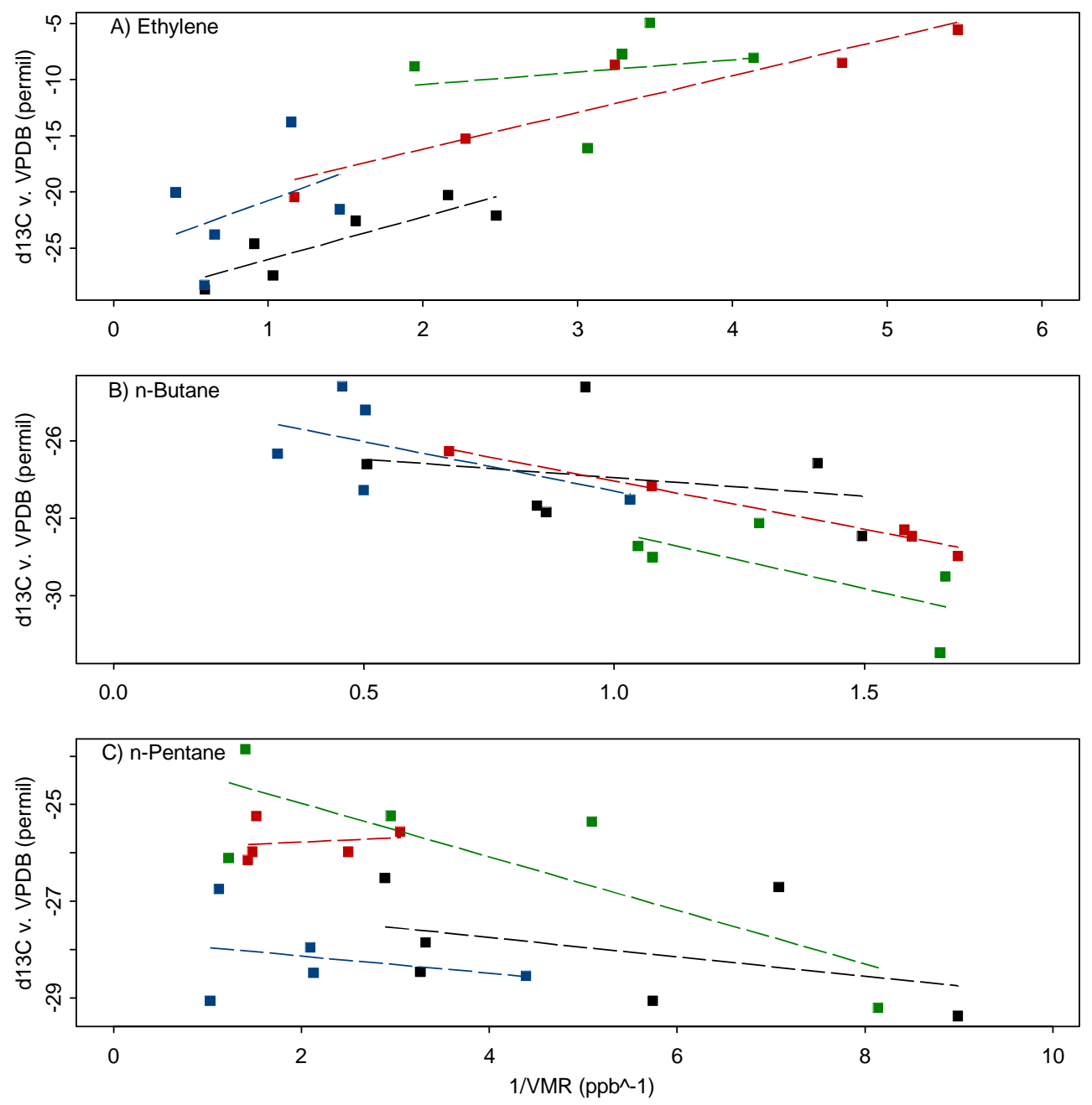

Fig. 9. Ethylene, n-butane, and n-pentane $\delta^{13} \mathrm{C}$ (\%o vs. VPDB) plotted versus inverse mixing ratio (ppb ${ }^{-1}$ ) over the 48-h (4-6 August 2009) period, with linear fits to points of each time period. Derived values for isotope source signatures are given in Table 5. Colors indicate periods as indicated in Fig. 7.

Table 5. Source signature (SS, in \%o vs. VPDB) and $r^{2}$ from fits in Fig. 9, 48-h measurements, 4 to 6 August 2009.

\begin{tabular}{lrrrrrrrrrr}
\hline Compound & SS all $(\% o)$ & $R^{2}$ all & SS P1 $^{\mathrm{a}}(\%)$ & $R^{2} \mathrm{P} 1$ & SS P2 $(\% o)$ & $R^{2} \mathrm{P} 2$ & SS P3 $(\% o)$ & $R^{2} \mathrm{P} 3$ & SS P4 $(\% o)$ & $R^{2} \mathrm{P} 4$ \\
\hline Ethylene & -26.8 & 0.68 & -29.8 & 0.76 & -25.7 & 0.17 & -12.6 & 0.04 & -22.7 & 0.89 \\
n-Butane & -24.7 & 0.52 & -26 & 0.07 & -24.7 & 0.29 & -25.4 & 0.47 & -24.5 & 0.98 \\
n-Pentane & -25.9 & 0.22 & -27 & 0.17 & -27.8 & 0.08 & -23.9 & 0.65 & -26 & 0.03 \\
\hline
\end{tabular}

a Periods are the same as in Table 3.

\section{Conclusions}

We have presented a NMHC stable carbon isotope analysis system capable of high-resolution measurements of many compounds from a large variety of sample sources with small measurement errors (1\%o vs. VPDB or less). In particular, the capability to process high volume atmospheric allows examination of samples with large quantities of bulk gases and
$\mathrm{CO}_{2}$, without loss of any compounds of interest, and with a short processing time as well. As the first results demonstrate, ${ }^{13} \mathrm{C}$ values measured during a 48 -h ambient air measurement campaign agree well with previous research, while highlighting the complex diurnal behavior of hydrocarbons in an urban environment. This on the one hand demonstrates reliable operation of the system and on the other opens the doorway to exciting future measurements. 
Acknowledgements. We would like to thank Henk Jansen, of Rijksuniversiteit Groningen, The Netherlands, for calibration of the $\mathrm{CO}_{2}$ reference standard; and Iulia Gensch, of Forschungscentrum Jülich, Germany, for calibration of the NMHC working standard.

Edited by: D. Riemer

\section{References}

Anderson, R. S., Huang, L., Iannone, R., Thompson, A. E., and Rudolph, J.: Carbon kinetic isotope effects in the gas phase reactions of light alkanes and ethene with the $\mathrm{OH}$ radical at $296 \pm 4 \mathrm{~K}$, J. Phys. Chem. A, 108, 11537-11544, doi:10.1021/JP0472008, 2004.

Archbold, M. E., Redeker, K. R., Davis, S., Elliot, T., and Kalin, R. M.: A method for carbon stable isotope analysis of methyl halides and chlorofluorocarbons at pptv concentrations, Rapid Commun. Mass Sp., 19, 337-340, doi:10.1002/rcm.17, 2005.

Atkinson, R., Baulch, D. L., Cox, R. A., Crowley, J. N., Hampson, R. F., Hynes, R. G., Jenkin, M. E., Rossi, M. J., Troe, J., and IUPAC Subcommittee: Evaluated kinetic and photochemical data for atmospheric chemistry: Volume II - gas phase reactions of organic species, Atmos. Chem. Phys., 6, 3625-4055, doi:10.5194/acp-6-3625-2006, 2006.

Bill, M., Rhew, R. C., Weiss, R. F., and Goldstein, A. H.: Carbon isotope ratios of methyl bromide and methyl chloride emitted from a coastal salt marsh, Geophys. Res. Lett., 29(4), 4 pp., doi:10.1029/2001GL012946, 2002.

Brenninkmeijer, C. A. M.: Applications of stable isotope analysis to atmospheric trace gas budgets, Eur. Phys. J. C, 1, 137-148, doi:10.1140/epjconf/e2009-00915-x, 2009.

Conny, J. M. and Currie, L. A.: The isotopic characterization of methane, non-methane hydrocarbons and formadehyde in the troposphere, J. Atmos. Environ., 30(4), 621-638, 1996.

Czapiewski, K. V., Czuba, E., Huang, L., Ernst, D., Norman, A. L., Koppmann, R., and Rudolph, J.: Isotopic composition of nonmethane hydrocarbons in emissions from biomass burning, J. Atmos. Chem., 43, 45-60, 2002.

Fisseha, R., Spahn, H., Wegener, R., Hohaus, T., Brasse, G., Wissel, H., Tillmann, R., Wahner, A., Koppmann, R., and KiendlerScharr, A.: Stable carbon isotope composition of secondary organic aerosol from $\beta$-pinene oxidation, J. Geophys. Res., 114, D02304, doi:10.1029/2008JD011326, 2009.

Goldstein, A. H. and Galbally, I. E.: Known and unexplored organic constituents in the Earth's atmosphere, Environ. Sci. Technol., 41(5), 1514-1521, doi:10.1021/es072476p, 2007.

Goldstein, A. H. and Shaw, S. L.: Isotopes of volatile organic compounds: an emerging approach for studying atmospheric budgets and chemistry, Chem. Rev., 103, 5025-5048, 2003.

Guenther, A., Hewitt, C. N., Erickson, D., Fall, R., Geron, C., Graedel, T., Harley, P., Klinger, L., Lerdau, M., McKay, W. A., Pierce, T., Scholes, B., Steinbrecher, R., Tallamraju, R., Taylor, J., and Zimmerman, P.: A global-model of natural volatile organic-compound emissions, J. Geophys. Res.-Atmos., 100, 8873-8892, 1995.

Harper, D. B., Hamilton, J. T. G., Ducrocq, V., Kennedy, J. T., Downey, A., and Kalin, R. M.: The distinctive isotopic signature of plant-derived chloromethane: possible application in con- straining the atmospheric chloromethane budget, Chemosphere, 52, 433-436, doi:10.1016/S0045-6535(03)00206-6, 2003.

Iannone, R., Anderson, R. S., Rudolph, J., Huang, L., and Ernst, D.: The carbon kinetic isotope effects of ozone-alkene reactions in the gasphase and the impact of ozone reactions on the stable carbon isotope ratios of alkenes in the atmosphere. Geophys. Res. Lett., 30(13), 1684-1688, doi:10.1029/2003GL017221, 2003.

Jardine, K. J., Karl, T., Lerdau, M., Harley, P., Guenther, A., Mak, J. E.: Carbon isotope analysis of acetaldehyde emitted from leaves following mechanical stress and anoxia, Plant Biology, 11(4), 591-597, doi:10.1111/j.1438-8677.2008.00155.x, 2009.

Keeling, C. D.: The concentration and isotopic abundances of atmospheric carbon dioxide in rural areas, Geochim. Cosmochim. Acta, 13, 322-334, 1958.

Keppler, F., Harper, D. B., Röckmann, T., Moore, R. M., and Hamilton, J. T. G.: New insight into the atmospheric chloromethane budget gained using stable carbon isotope ratios, Atmos. Chem. Phys., 5, 2403-2411, doi:10.5194/acp-5-2403-2005, 2005.

Lu, Y. and Khalil, M. A. K.: Tropospheric OH: model calculations of spatial, temporal, and secular variations, Chemosphere, 23, 397-444, 1991.

Matthews, D. M. and Hayes, J. M.: Isotope-ratio-monitoring gas chromatography-mass spectrometry, Anal. Chem., 50(11), 1465-1473, 1978.

Middleton, P.: Sources of air pollutants, in: In Composition, Chemistry, and Climate of the Atmosphere, edited by: Singh, H. B., John Wiley \& Sons Inc., New York, 88-119, 1995.

Milton, M. J. T., Harris, P. M., Brown, A. S., and Cowper, C. J.: Normalization of natural gas composition data measured by gas chromatography, Meas. Sci. Technol., 20, 025101, doi:10.1088/0957-0233/20/2/025101, 2010.

Nara, H., Nakagawa, F., and Yoshida, N.: Development of twodimensional gas chromatography/ isotope ratio mass spectrometry for the stable carbon isotopic analysis of C2-C5 non methane hydrocarbons emitted from biomass burning, Rapid Commun. Mass Sp., 20, 241-247, doi:10.1002/rcm.2302, 2006.

Nara, H., Toyoda, S., and Yoshida, N.: Measurements of stable carbon isotopic composition of ethane and propane over the Western North Pacific and Eastern Indian Ocean: a useful indicator of atmospheric transport process, J. Atmos. Chem., 56, 293-314, doi:10.1007/s10874-006-9057-3, 2007.

Redeker, K. R., Davis, S., and Kalin, R. M.: Isotope values of atmospheric halocarbons and hydrocarbons from Irish urban, rural, and marine locations, J. Geophys. Res., 112, D16307, doi:10.1029/2006JD007784, 2007.

Röckmann, T., Kaiser, J., Brenninkmeijer, C. A. M., and Brand, W. A.: Gas-chromatography, isotope-ratio mass spectrometry method for high-precision position-dependent ${ }^{15} \mathrm{~N}$ and ${ }^{18} \mathrm{O}$ measurements of atmospheric nitrous oxide, Rapid Commun. Mass Spectrom., 17, 1897-1908, 2003.

Rudolph, J. and Czuba, E.: On the use of isotopic composition measurements of volatile organic compounds to determine the "photochemical age" of an air mass, Geophys. Res. Lett., 27(23), 3865-3868, 2000.

Rudolph, J. and Ehhalt, D. H.: Measurements of C2-C5 hydrocarbons over the North Atlantic, J. Geophys. Res., 86(C12), 1195911964, 1981.

Rudolph, J., Lowe, D. C., Martin, R. J., and Clarkson, T. S.: A novel method for compound specific determination of $13 \mathrm{C}$ in volitile 
organic compunds at ppt levels in ambient air, Geophys. Res. Lett., 24(6), 659-662, 1997.

Rudolph, J., Czuba, E., Norman, A. L., Huang, L., and Ernst, D.: Stable carbon isotope composition of nonmethane hydrocarbons in emissions from transportation related sources and atmospheric observations in an urban atmosphere, Atmos. Environ., 36, 1173-1181, 2002.

Saito, T., Tsunogai, U., Kawamura, K., Nakatsuka, T., and Yoshida, N.: Stable carbon isotopic compositions of light hydrocarbons over the Western North Pacific and implication for their photochemical ages, J. Geophys. Res., 107(D4), 4040, doi:10.1029/2000JD000127, 2002.

Saito, T., Kawamura, K., Tsunogai, U., Chen, T., Matsueda, H., Nakatsuka, T., Gamo, T., Uematsu, M., and Huebert, B. J.: Photochemical histories of nonmethane hydrocarbons inferred from their stable carbon isotope ratio measurements over east Asia, J. Geophys. Res., 114, D11303, doi:10.1029/2008JD011388, 2009.
Santrock, J., Studley, S. A., and Hayes, J. M.: Isotopic analyses based on the mass spectra of carbon dioxide, Anal. Chem., 57(7), 1444-1448, doi:10.1021/ac00284a060, 1985.

Seinfeld, J. H. and Pandis, S. N.: Atmospheric Chemistry and Physics: from Air Pollution to Climate Change, John Wiley and Sons, New York, 1326 pp., 1998.

Skrbic, B. D. and Zlatkovic, M. J.: Simple method for the rapid analysis of natural gas by gas chromatography, Chromatographia, 17(1), 44-46, 1983.

Tsunogai, U. and Yoshida, N.: Carbon isotopic compositions of C2-C5 hydrocarbons and methyl chloride in urban, coastal, and maritime atmospheres over theWestern North Pacific, J. Geophys. Res., 104(D13), 16033-16039, 1999.

Warneck, P.: Chemistry of the Natural Atmosphere, Academic Press, San Diego, CA, 757 pp., 1988. 